\title{
Urethral funneling visualized during pelvic floor sonography - analysis of occurrence among urogynecological patients
}

\author{
Edyta Wlaźlak ${ }^{1}$, Tomasz Kluz², Grzegorz Surkont ${ }^{1}$, Jacek Kociszewski ${ }^{3}$ \\ ${ }^{1}$ Clinic of Operative Gynecology and Gynecologic Oncology, 1st Department of Gynecology and Obstetrics, \\ Medical University of Lodz, Poland \\ ${ }^{2}$ Department of Obstetrics and Gynecology, Fryderyk Chopin University Hospital No. 1, Faculty of Medicine, \\ Rzeszow University, Rzeszow, Poland \\ ${ }^{3}$ Department of Gynecology and Obstetrics, Lutheran Hospital Hagen-Haspe, Hagen, Germany
}

\begin{abstract}
Objectives: There are different diagnostic methods used in women with urinary incontinence symptoms such as: medical history, voiding diary, cough test, pad test, urodynamic testing. None of them is optimal.

The aim of this study is to analyze the correlation between urethral funneling visualized during pelvic floor sonography and symptoms of stress urinary incontinence.

Material and methods: We have performed a retrospective analysis of 657 complete datasets of patients who attended our urogynecological clinic for diagnostics. Women with wet overactive bladder were excluded from the analysis. Tests used in our clinic included: standardized interview and questionnaire, clinical exam, cough test. Pelvic floor sonography with a transvaginal probe in women with filled bladder was performed to assess the urethral length and the urethral funneling during maximal Valsalva maneuver.

Results: In all patients with clinical SUI symptoms and with a positive cough test the urethral funneling length during Valsalva maneuver was $>50 \%$ of urethral length (long urethral funneling). In $83.7 \%$ of women without SUI the urethral funneling was absent. In the remaining $16.3 \%$ funneling was visible but its relative length was less than $50 \%$ of urethral length and urine flow was not observed (short urethral funneling).

Conclusions: Long urethral funneling (> $50 \%$ of urethral length) seems to be a characteristic sign for SUI in women. The presence of urethral funneling shorter than $50 \%$ of urethral length (short urethral funneling) is not a SUI symptom - it is probably a sign of asymptomatic funneling of bladder neck.
\end{abstract}

Key words: ultrasound, female, pelvic floor sonography, transvaginal probe, urethral funneling, stress urinary incontinence

Ginekologia Polska 2018; 89, 2: 55-61

\section{INTRODUCTION}

Urinary incontinence (UI) in women is treated differently according to type and cause, which may be various. The most common type of $\mathrm{Ul}$ is stress urinary incontinence (SUI), which may be treated operatively [1, 2, 3]. It is important to make a proper differential diagnosis of SUI, especially before the operation. There exist different urinary incontinence diagnostic methods, for example: interview, voiding diary, cough test, pad test, assessment of residual urine after voiding or urodynamic testing. However, none of them is optimal [1,4-10].

Making a diagnosis of SUI in women by means of taking history is characterized by high reliability (kappa $=0.8 ; 95 \%$ $\mathrm{Cl}, 0.3-0.9$ ) and a high rate of conformity between repeated questioning (about 90\%). However, it is widely accepted agree that this is not sufficient $[2,4,7]$. Bladder diary is not proven to be valid for the prediction of incontinence type. Additionally, some patients experience difficulty in 
completing the diary and it is not easy to analyze symptoms, especially if they do not occur every day $[7,9]$. Cough test should be performed with a full bladder in lying or standing position. A positive result of such test increases the probability of SUI ( $(\mathrm{R}, 3.1 ; 95 \% \mathrm{Cl}, 1.7-5.5)$, while a negative test result decreases it $(\mathrm{LR}, 0.36 ; 95 \% \mathrm{Cl}, 0.21-0.60)[7,8]$. Data to evaluate the test performed with a Valsalva maneuver compared to coughing is not available. Pad test was found to be useful to diagnose UI but not to diagnose the type of UI [7]. There are different tests used during urodynamic examination to confirm SUl: cough leak point pressure (CLPP), Valsalva leak point pressure (VLPP) or stress profilometry. Yet, none of them is standardized sufficiently $[7,8]$. Post-void residual of urine, which may be measured by catheterization or by ultrasound, is helpful to diagnose or exclude overflow incontinence, but not to diagnose SUI $[7,8]$.

During radiological urethrocystography and pelvic floor ultrasound examination of patients with symptoms of SUI urethral funneling is often visible [11-13]. There are conflicting data on the clinical significance of the urethral funneling in the literature regarding this subject. Among the patients with SUI clinical symptoms, the frequency of urethral funneling ranged from $18.6 \%$ to $100 \%$ [10-17]. Some authors present opinion that the presence of urethral funneling is typical for patients with an intrinsic sphincter deficiency (ISD) $[2,11,12]$. Also, there are studies showing that a suburethral tape implantation that effectively treated SUI in patients have also often eliminated the funneling. If the funneling persisted after the suburethral tape implantation, it was found to be a risk factor for failure of SUI surgical treatment [13, 18-20]. Some experts managed to visualize urethral funneling also in cases after a successful treatment with suburethral tape [18-20].

Ultrasound is more often used during urogynecologic examinations. In many urogynecologic centers 2D and 4D ultrasound performed translabially with a transabdominal probe is used [8, 21, 22]. In the latest guideline for German speaking countries an expert panel advocate that 2D ultrasound is especially useful in urinary incontinent patients [23]. In our opinion 2D ultrasound performed with a transvaginal probe (PFS-TV) may be used in urogynecological centers more often because many specialists are familiar with a transvaginal probe, which offers real time high quality images with a minimal influence on female pelvic floor [23-26].

In our previous study we found that the urethral funneling with urine flow was visible in all of the patients with SUI of $2^{\text {nd }}$ and $3^{\text {rd }}$ degree who were examined by PFS-TV before the suburethral tape insertion. From among patients treated successfully with the tape insertion, in $76.9 \%$ of them urethral funneling was not visible. In the rest the urethral funneling has persisted but was shorter and the urine flow was not visible. The width of funneling postoperatively remained unchanged. Interestingly, in cases where treatment failed, urethral funneling with urine flow has persisted and parameters of urethral funneling (length and width) have remained the same as before the operation [19].

In this study we wanted to analyze the results of PFS-TV examination focusing on the presence of funneling with flow of urine in the general population of urogynecological patients who attended our outpatient clinic.

\section{OBJECTIVES}

The aim of this study is to analyze the correlation between urethral funneling visualized during pelvic floor sonography and symptoms of stress urinary incontinence (SUI).

\section{MATERIAL AND METHODS}

We performed a retrospective analysis of 657 complete datasets of patients who attended our urogynecological clinic for diagnostics after excluding women with wet overactive bladder $(\mathrm{n}=9)$.

Typical tests used in our clinic included:

- standardized in-house non-validated interview and questionnaire,

- clinical exam using the ICS POP-Q [27, 28],

- cough test,

- pelvic floor sonography performed with a transvaginal probe (PFS-TV).

Significant prolapse was defined as a prolapse $\geq$ stage $2(2+)$.

Cough test was performed in patients in lithotomy position with $250-350 \mathrm{~mL}$ of urine in the bladder. If the test was negative, it was repeated in standing. The volume of urine in the bladder was evaluated with a transabdominal ultrasound by performing three-plane bladder measurements that were calculated by the ultrasound system. Patient was classified as SUIO group if she reported no SUI symptoms at home and sitting and standing cough tests were negative. We classified patients to SUI + group if symptoms of stress urinary incontinence were reported and sitting or standing cough test was positive.

PFS-TV was performed in female patients with a bladder filling of $250-350 \mathrm{~mL}$ on a gynecological chair in a semi-sitting position using the introital approach in accordance with the standardized technique developed by Kociszewski. A high-frequency transvaginal probe $(6.5 \mathrm{MHz}$, beam angle $160^{\circ}$ ) was used for the evaluation. Urethral length measurement was performed at rest in a sagittal plane (Fig. 1). The probe was placed near the external urethral ostium with minimal probe compression on the investigated surface [24-26]. After rotating the probe to optimize bladder neck visualization and to obtain optimal angle for ultrasonic wave, urethral funneling and urine flow was observed dur- 
A
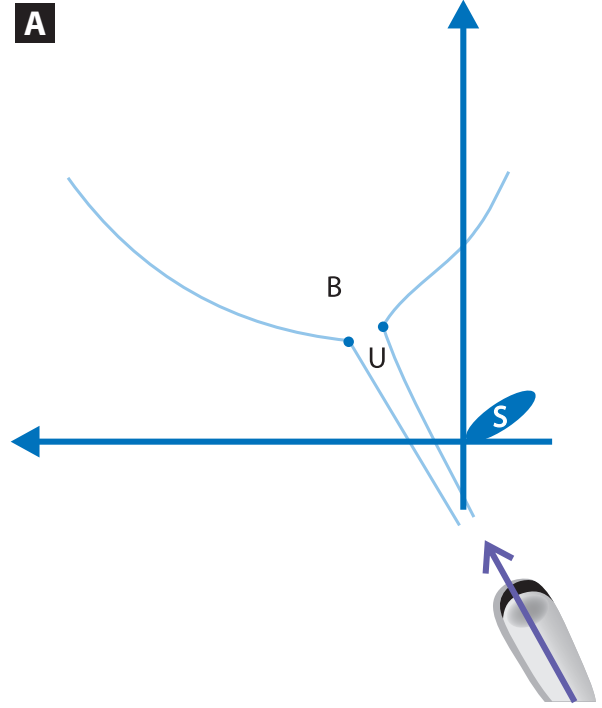

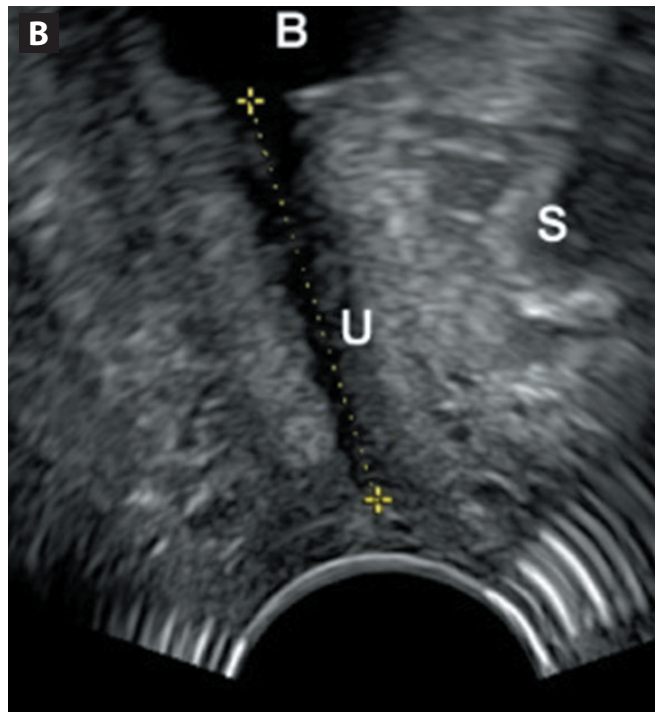

Figure 1A, 1B. Picture of a transvaginal probe setting in sagittal plane to measure urethral length and obtained ultrasound picture (PFS-TV). A. Scheme of the transvaginal probe placement $\mathbf{B}$. The obtained ultrasound image

S - symphysis pubis, B — bladderU — urethra

ing maximal Valsalva maneuver (Fig. 2). The Valsalva maneuver lasted at least 5 seconds. If the test was negative, Valsalva was repeated 2 times. If the patient was not able to perform Valsalva maneuver, she was asked to cough vigorously 5 times.

In our opinion, in the past authors did not really measure length of the opened urethra, which was represented, according to them, by the height of the triangle of the urethral funneling $[11,13,15,16]$. This height started in the middle of the section 1, and finished in the right end of section 5 on Figure $2 \mathrm{C}$. To calculate the percentage of the opened urethra we needed more accurate parameter. That is why, we introduced and analyzed a new way of measurement of the urethral funneling, which is presented on Figure $2 \mathrm{C}$.

As the width we measured section 1 on Figure $2 \mathrm{C}$, as the length - we measured sections $2-5$ (the length of the urethral edge which was more distant from the probe). Our earlier analysis proved that the measurements of the urethral edge more distant from the probe (section $2-5$ on Fig. 2c) were more repeatable than measurements of the border closer to the probe (not measured funneling border opposite to section 2-5 on Fig. 2c). It results from the fact that the edge of the beginning of the funneling more distant from the probe (right end of section 1, connected with section 2) was more rough, which made it more visible compared to the edge of the funneling closer the probe (left beginning of section 1). The shapes of the urethral border closer to the probe differed between patients, while the distant ones - were the same in the case of all of the patients. What is more, urethral funneling sections closer to the probe were longer than the ones more distant from the probe. Even in some cases, the length of the opened part of the urethra closer to the probe was longer than urethral length itself, which should not be impossible.

In our opinion, the above presented observations prove that the funneling border closer to the probe does not really represent the length of opened urethra. We suspect that changing of the shape of this urethral border is caused by its extension, which is another factor that makes measurements of this border less accurate.

For the estimation of the percentage of opened urethra, new geometrical parameter was introduced. We called it "relative urethral funneling length". It was calculated as the percentage ratio of the urethral funneling length to the sonographic urethral length according to formula [1]:

Relative urethral funneling length = funneling length * $100 \%$ / sonographic urethral length.

For statistical analysis we used packages of descriptive statistics and Student's t-test for testing the significance of differences between independent samples. The calculations were performed in Statistica program of StatSoft (version 7.1).

\section{RESULTS}

In 447 cases (68\%) there were no clinical signs of SUI (SUI0). SUI was diagnosed in 210 cases (32\%) - SUI+. There were no significant differences in the distribution of age, $\mathrm{BMI}$, number and mode of deliveries between the groups SUIO and SUI+. The mean age in SUI0 group was 50 years (range $=19$ to 86 ), in SUI \pm 49 years (range $=22$ to 82 ). The mean BMI in both groups was $27 \mathrm{~kg} / \mathrm{m}^{2}$ (in SUI0 group range $=16-41$, in SUI $\pm 17-39$ ). The mean parity in both 

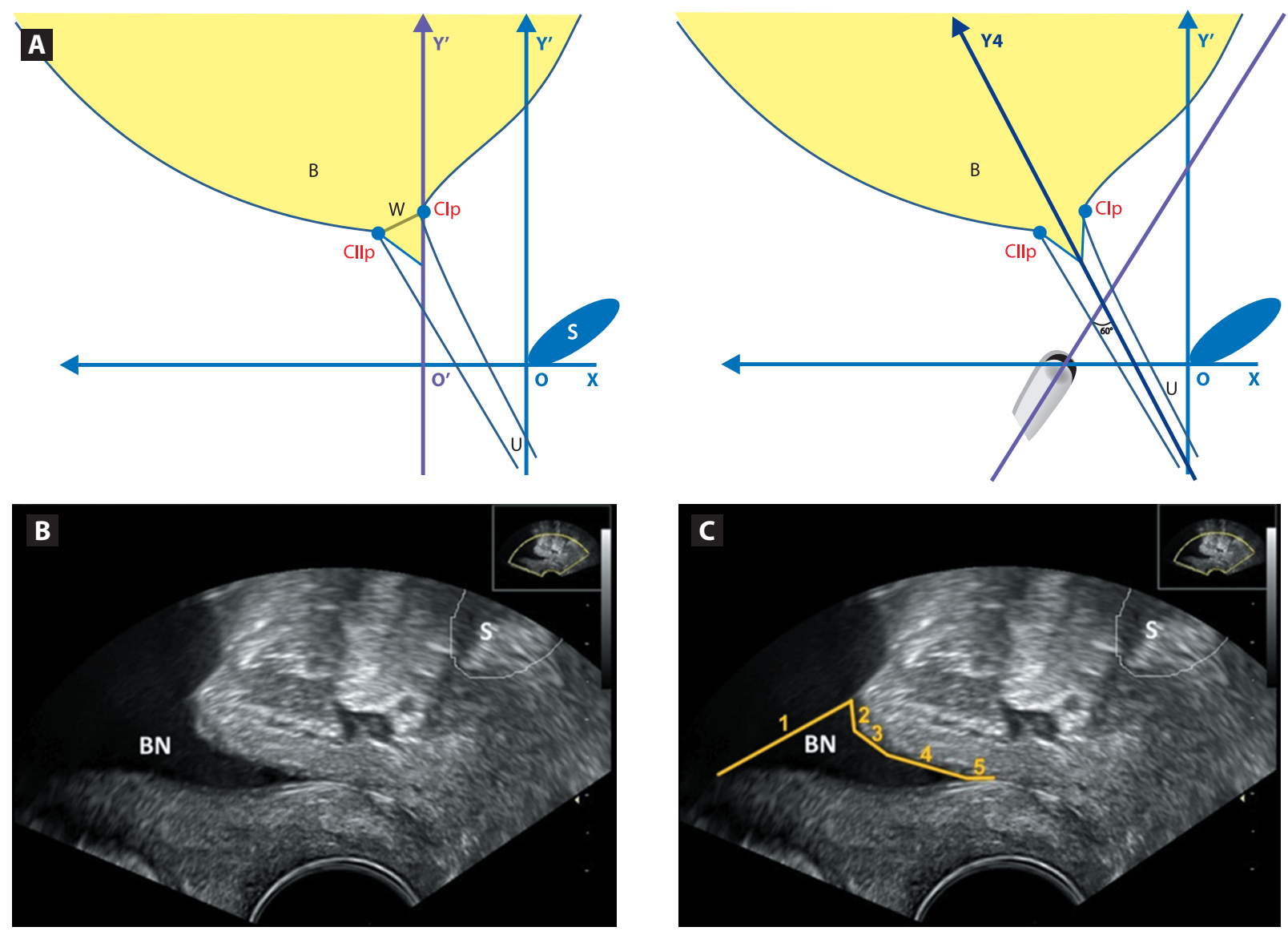

Figure 2A, 2B, 2C. Picture of the transvaginal probe setting in sagittal plane to visualize urethral funneling with urine flow and obtained ultrasound image of urethral funneling during Valsalva maneuver (PFS-TV). A. Scheme of the transvaginal probe setting and measurement of urethral funneling B. Obtained ultrasound image of the urethral funneling $C$. Measurement of the length and the width of urethral funneling

$\mathrm{S}$ - symphysis pubis, $\mathrm{B}$ - bladder, $\mathrm{U}$ - urethra, $\mathrm{BN}$ - bladder neck, $\mathrm{Cl}_{\mathrm{p}}$ and $\mathrm{Cll}_{\mathrm{p}}$ - points locating bladder neck during Valsalva maneuver, $\mathrm{W}-$ urethral funneling width, 1 - urethral funneling width, $2+3+4+5-$ urethral funneling length

groups was 2 (in SUI0 group range $=0-6$, in SUI+ range $=0-5$ ). $79.2 \%$ of women from SUI0 group were vaginally parous, while $84.8 \%$ from SUI+ group. A Vacuum or Forceps was reported by $6.3 \%$ patients from SUI0 group, $5.2 \%$ from SUI+ group, cesarean section by $25.5 \%$ from SUI0 group, $30.0 \%$ from SUI+ group, nulliparous by $4.0 \%$ from SUI0 group, $2.9 \%$ from SUI+ group.

$14.5 \%$ of analyzed women from SUI0 group were after hysterectomy, $9.0 \%$ - from SUI+ group ( $p=0.017) .71 .4 \%$ of patients from SUI0 group were after minimum one urogynecological operation, while only $50.5 \%$ from SUI+ group $(p=0.0000)$.

The differences in occurrence of significant clinical cystocele and rectocele between groups SUIO and SUI+ were statistically significant, respectively $p=0.003$ and $p=0.0002$. On examination of women from SUI0 group a cystocele stage $2+$ was found in $27.7 \%$, significant central compartment prolapse in $5.6 \%$, and a significant clinical rectocele in $29.5 \%$. On examination of patients from SUI+ group a significant cystocele was found in $17.6 \%$, central compartment prolapse in $4.3 \%$, and rectocele in $16.7 \%$.

There were no statistically significant differences in urethral length between the groups. The median for SUI0 group was $31.1[\mathrm{~mm}]$ (18.7-43.8) and $31.3[\mathrm{~mm}](18.1-50.9)$ for the SUI+ group.

Urethral funneling together with the urine flow was visible in all the patients from group SUI+ during Valsalva or coughing. In all of these patients the relative funneling length was longer than $50 \%$ of urethral length: median $=54.7 \%$ (50.1-100\%). The median of funneling length was $16.9 \mathrm{~mm}$ (11.0-39.5).

In most of the patients from SUI0 group (83.7\%) the urethral funneling was not present. In the remaining $16.3 \%$ funneling was visible but without urine flow. Also, the relative funneling length was shorter than $50 \%$ of urethral length in all the patients from SUI0 group: median $=24.0 \%$ (6.9-49.7\%). The median of funneling length was $7.0 \mathrm{~mm}$ (1.9-18.1). The patients from SUI0 group with the urethral 
funneling of $<50 \%$ of urethral length did not report any overactive bladder symptoms.

There were statistically significant differences in funneling length and in relative funneling length between patients from group SUI0 and group SUI+ $(p<0.0000)$.

There were no statistically significant differences in urethral funneling width between SUIO and SUI+ groups. The median funneling width was $4.9 \mathrm{~mm}(1.5-12.3)$ for the SUI0 group and $5.5 \mathrm{~mm}$ (1.2-16.6) for the SUI+ group.

\section{DISCUSSION}

There is no optimal diagnostic test for stress urinary incontinence. Currently, performing a few tests and a comprehensive analysis of the results is necessary to diagnose SUI $[1,2,7,8,10]$.

Ultrasound examination is more often used for diagnosing urogynecological patients. An advantage of ultrasound is the possibility of multiple repetitions in a short time with close contact with the patient and a real-time evaluation [18, $22,23,26,29]$. The transvaginal probe has a high resolution, but a short range. However, for SUI the diagnostic range of transvaginal probe is sufficient enough to visualize the urethra and the bladder neck [23-26]. In our opinion using a small transvaginal probe outside the vagina minimizes the influence of the probe on the pelvic floor changes that occur during Valsalva maneuver or Kegel's exercises.

So far the significance of urethral funneling in urogynecological patients was not determined. Researchers report different frequency of visualizing urethral funneling in patients with clinical SUI symptoms. The funneling is visualized in $18.6 \%$ to $100 \%$ of cases [10-17]. In our opinion such a large diversity of results may be caused by differences in the methodology and conditions of performing pelvic floor ultrasound, for example the amount of urine in the bladder and the angle of the ultrasound beam. Harms et al. suggested that the use of contrast during ultrasound examination of a patient with a filled bladder improved the quality of visualized bladder neck area. In author's opinion such examination makes the urethral funneling visible more often [13]. However, it is well known that any fluid or urine itself is usually a sufficient contrast in ultrasonography. For example a spontaneous occurrence of fluid within the uterine cavity allows a very accurate visualization of the uterine cavity and the endometrium. Saline is used as a very good contrast that is helpful in visualizing the uterine cavity and the endometrium during saline infusion sonography (SIS) $[30,31]$. The angle of the ultrasound beam has a significant impact on the quality of images hence accuracy of measurements. For example the visualization of nuchal translucency and its accurate measurement is only possible with an appropriate angle of the ultrasound beam and only after obtaining the appropriate section [32]. In our study the transducer was rotated downwards in order to visualize better the neck of the bladder, which, in our opinion, has a positive effect on the visibility of the urethral funneling. We tried to achieve a minimum 60-degree angle between the transducer and the urethra, which, in our opinion, is sufficient (Fig. 2). Although the optimal angle is 90 degrees, in many patients this is not possible to achieve, which may depend on urethral mobility and hiatal dimensions. We did not analyze it statistically but our observations suggest that if the angle is $<60$ degrees, the chances to miss the funneling are bigger. In other words the smaller the angle (less than 60 degrees), the bigger the risk of not visualizing the existing urethral funneling. PFS-TV was performed in patients with a full bladder so urine itself was our contrast. When performing a cough test or an urodynamic examination of urinary incontinence, patients' bladder should be full $[1,7,8]$. Yet, some of the experts may evaluate the presence of urethral funneling on an empty bladder as authors of some studies did not measure the degree of bladder filling when the visibility of urethral funneling was evaluated [13, 33]. In our patients the bladder was filled with $250-350 \mathrm{~mL}$ during the examination with PFS-TV.

In our study we have confirmed that the urethral funneling longer than $50 \%$ of urethral length, which is visible during Valsalva maneuver (PFS-TV), coexists with urine flow. Also, urethral funneling that was longer than $50 \%$ of urethral length was observed in all of the patients from SUI+ group. In contrast, in most of SUI0 patients the urethral funneling was not observed. In such case, during PFS-TV, the urine flow was not observed either. Although in $16.3 \%$ of patients from SUI0 group the urethral funneling was visible, it was shorter than $50 \%$ of urethral length and during PFS-TV the urine flow was not observed either.

In all of the patients from SUI+ group the relative urethral funneling length was over $50 \%$. In all of the women from SUI0 group the relative urethral funneling length was less than $50 \%$. The width of urethral funneling did not show clinically important statistical significance. Based on the results of our study we propose to define and use two new terms: "short" and "long" urethral funneling. Short urethral funneling is the funneling of urethral neck in the absence of stress urinary incontinence. In such case the length of the urethral funneling is shorter than $50 \%$ of urethral length hence there is no urine outflow observed. In turn, a long urethral funneling corresponds to funneling with urine flow, which was a characteristic in women with clinical signs of stress urinary incontinence. Such funneling is longer than $50 \%$ of urethral length and that's why patients have stress urinary incontinence. We did not find any correlation between the width of the funneling and SUI. Ulmsten and Petros found that a high-pressure zone is localized in the middle of the urethra (at about $50 \%$ of the urethral length) 
and that it stands behind the urinary continence [34, 35]. Our observations are in line with theirs and confirm that. We believe that when the bladder neck is opening, urethral funneling begins to occur. If it takes long enough to reach the high-pressure zone in the middle of the urethra (about 50\% of urethral length), urine flows outside. That is why a long urethral funneling is visible in women with SUI, while a short urethral funneling is not a symptom of SUI. We believe our results confirm that long urethral funneling can be clinically useful to confirm SUI.

There exist some limitations of our study. The analysis was retrospective. Our clinic performs the urodynamic examination in selected cases only. This is why most of our patients included in the analysis did not have this exam. The results of the urodynamic examination would have enabled us to include the urodynamic SUI as well as patients with ISD into the comparative analysis. However, this would diminish the number of analyzed patients, especially in SUI0 group. Another problem is the significance of urodynamic SUI, which is full of controversy while the definition of ISD is also a source of dispute $[7,8,12]$. We did not include into the analysis stages of pelvic organ prolapse using POP-Q $[27,28]$, because we did not evaluate occult incontinence. Despite these shortcomings, we have demonstrated for the first time the potential usefulness of long funneling detected during PFS-TV in confirming SUI in the general population of urogynecologic patients. Our findings need to be confirmed in prospective studies in urogynecologic patients before and after surgery and with complex diagnostics including an urodynamic test.

\section{CONCLUSIONS}

Long urethral funneling ( $>50 \%$ of urethral length) seems to be a characteristic sign for SUI in women. The presence of urethral funneling shorter than $50 \%$ of urethral length (short urethral funneling) is not a SUI symptom - it is probably a sign of asymptomatic funneling of bladder neck.

\section{REFERENCES}

1. Garely AD, Noor N. Diagnosis and surgical treatment of stress urinary incontinence. Obstet Gynecol. 2014; 124(5): 1011-1027, doi: 10.1097/AOG.0000000000000514, indexed in Pubmed: 25437731.

2. Holroyd-Leduc JM, Tannenbaum C, Thorpe KE, et al. What type of urinary incontinence does this woman have? JAMA. 2008; 299(12): 1446-1456, doi: 10.1001/jama.299.12.1446, indexed in Pubmed: 18364487.

3. Surkont G, Wlaźlak E, Petri E, et al. Standardized modified colposuspension--mid-term results of prospective studies in one centre. Ann Agric Environ Med. 2015; 22(2): 293-296, doi: 10.5604/12321966.1152082, indexed in Pubmed: 26094526.

4. Rohr G, Christensen K, Ulstrup K, et al. Reproducibility and validity of simple questions to identify urinary incontinence in elderly women. Acta Obstet Gynecol Scand. 2004; 83(10): 969-972, doi: 10.1111/j.0001-6349.2004.00557.x, indexed in Pubmed: 15453896.

5. Surkont G, Wlaźlak E, Suzin J. Long-term risk of complications after mid-urethral sling IVS implantation. Ann Agric Environ Med. 2015; 22(1): 163-166, doi: 10.5604/12321966.1141388, indexed in Pubmed: 25780848 .
6. Stangel-Wojcikiewicz K, Piwowar M, Jach R, et al. Quality of life assessment in female patients 2 and 4 years after muscle-derived cell transplants for stress urinary incontinence treatment. Ginekol Pol. 2016; 87(3): 183-189, doi: 10.17772/gp/61330, indexed in Pubmed: 27306126.

7. Staskin D, Kelleher C, Avery K, Cardozo L, Khoury S, Wein A. et al.. Initial Assessment of Urinary and Faecal Incontinence in Adult Male and Female Patients. In: Abrams P, Cardozo L, Khoury S, Wein A. ed. Incontinence. Health Publication Ltd 2009: 331-412.

8. Wlaźlak E, Surkont G, Shek KaL, et al. Can we predict urinary stress incontinence by using demographic, clinical, imaging and urodynamic data? Eur J Obstet Gynecol Reprod Biol. 2015; 193: 114-117, doi: 10.1016/j. ejogrb.2015.07.012, indexed in Pubmed: 26291686.

9. Bright $E$, Drake MJ, Abrams P. Urinary diaries: evidence for the development and validation of diary content, format, and duration. Neurourol Urodyn. 2011; 30(3): 348-352, doi: 10.1002/nau.20994, indexed in Pubmed: 21284023.

10. Tannenbaum C, Corcos J. Outcomes in urinary incontinence: reconciling clinical relevance with scientific rigour. Eur Urol. 2008; 53(6): 1151-1161, doi: 10.1016/j.eururo.2008.02.013, indexed in Pubmed: 18328618.

11. Versi E. The significance of an open bladder neck in women. Br J Urol. 1991; 68(1): 42-43, doi: 10.1111/j.1464-410x.1991.tb15254.x, indexed in Pubmed: 1873690.

12. Ghoniem GM, Elgamasy AN, Elsergany $R$, et al. Grades of intrinsic sphincteric deficiency (ISD) associated with female stress urinary incontinence. Int Urogynecol J Pelvic Floor Dysfunct. 2002; 13(2): 99-105; discussion 105, doi: 10.1007/s001920200023, indexed in Pubmed: 12054190.

13. Harms L, Emons G, Bader W, et al. Funneling before and after anti-incontinence surgery--a prognostic indicator? Part 2: tension-free vaginal tape. Int Urogynecol J Pelvic Floor Dysfunct. 2007; 18(3): 289-294, doi: 10.1007/s00192-006-0147-1, indexed in Pubmed: 16847585.

14. Versi E, Cardozo L, Studd J, et al. Distal urethral compensatory mechanisms in women with an incompetent bladder neck who remain continent, and the effect of the menopause. Neurourol Urodyn. 1990; 9(6):579-590, doi: 10.1002/nau.1930090603.

15. Schaer GN, Perucchini D, Munz E, et al. Sonographic evaluation of the bladder neck in continent and stress-incontinent women. Obstet Gynecol. 1999; 93(3): 412-416, doi: 10.1097/00006250-199903000-00020, indexed in Pubmed: 10074990.

16. Tunn R, Goldammer K, Gauruder-Burmester A, et al. Pathogenesis of urethral funneling in women with stress urinary incontinence assessed by introital ultrasound. Ultrasound Obstet Gynecol. 2005; 26(3): 287-292, doi: 10.1002/uog.1977, indexed in Pubmed: 16082725.

17. Schaer GN, Koechli OR, Schuessler B, et al. Improvement of perineal sonographic bladder neck imaging with ultrasound contrast medium. Obstet Gynecol. 1995; 86(6): 950-954, doi: 10.1016/0029-7844(95)003017, indexed in Pubmed: 7501346.

18. Bergström BoS. Curative mechanisms of two tension-free vaginal tape positions. Theoretical comments based on the urethral hanging theory of female stress urinary incontinence. Neurourol Urodyn. 2017; 36(8): 2181-2183, doi: 10.1002/nau.23229, indexed in Pubmed: 28185298.

19. Wlazlak $E$, Viereck $V$, Surkont $G$, [et al.]. The significance of urethral funneling and urine flow (PF-ultrasound) in evaluating stress urinary incontinence [Abstract]. Poster ICS 2014; Rio de Janeiro. www.ics. org/Abstracts/Publish/218/000234.pdf (20th-24th October 2014).

20. Kluz T, WlaźlakE, Surkont G. Transvaginal six-arm mesh OPUR in women with apical pelvic organ prolapse - analysis of short-term results, pelvic floor ultrasound evaluation. Ginekol Pol. 2017; 88(6): 302-306, doi: 10.5603/GP.a2017.0057, indexed in Pubmed: 28727128.

21. Dietz HP, Shek C, Clarke B. Biometry of the pubovisceral muscle and levator hiatus by three-dimensional pelvic floor ultrasound. Ultrasound Obstet Gynecol. 2005; 25(6): 580-585, doi: 10.1002/uog.1899, indexed in Pubmed: 15883982.

22. Dietz HP, Bernardo MJ, Kirby A, et al. Minimal criteria for the diagnosis of avulsion of the puborectalis muscle by tomographic ultrasound. Int Urogynecol J. 2011; 22(6): 699-704, doi: 10.1007/s00192-010-1329-4, indexed in Pubmed: 21107811.

23. Tunn R, Albrich S, Beilecke K, et al. Interdisciplinary S2k Guideline: Sonography in Urogynecology: Short Version - AWMF Registry Number: 015/055. Geburtshilfe Frauenheilkd. 2014; 74(12): 1093-1098, doi: 10.1055/s-0034-1383044, indexed in Pubmed: 25568465.

24. Kociszewski J, Rautenberg O, Kuszka A, et al. Can we place tension-free vaginal tape where it should be? The one-third rule. Ultrasound Obstet Gynecol. 2012; 39(2): 210-214, doi: 10.1002/uog.10050, indexed in Pubmed: 21793084. 
25. Viereck V, Kuszka A, Rautenberg O, et al. Do different vaginal tapes need different suburethral incisions? The one-half rule. Neurourol Urodyn. 2015; 34(8): 741-746, doi: 10.1002/nau.22658, indexed in Pubmed: 25176293.

26. Wlaźlak E, Viereck V, Kociszewski J, et al. Role of intrinsic sphincter deficiency with and without urethral hypomobility on the outcome of tape insertion. Neurourol Urodyn. 2017; 36(7): 1910-1916, doi: 10.1002/nau.23211, indexed in Pubmed: 28139863.

27. Bump RC, Mattiasson A, Bø K, et al. The standardization of terminology of female pelvic organ prolapse and pelvic floor dysfunction. Am J Obstet Gynecol. 1996; 175(1): 10-17, doi: 10.1016/s0002-9378(96)70243-0, indexed in Pubmed: 8694033.

28. Lemos N, Korte JE, Iskander M, et al. Center-by-center results of a multicenter prospective trial to determine the inter-observer correlation of the simplified POP-Q in describing pelvic organ prolapse. Int Urogynecol J. 2012; 23(5): 579-584, doi: 10.1007/s00192-011-1593-y, indexed in Pubmed: 22083515.

29. Dietz HP. Pelvic floor ultrasound in incontinence: what's in it for the surgeon? Int Urogynecol J. 2011; 22(9): 1085-1097, doi: 10.1007/s00192011-1402-7, indexed in Pubmed: 21512829.

30. Goldstein SR. Postmenopausal endometrial fluid collections revisited: look at the doughnut rather than the whole. Obstet Gynecol. 1994; 83(5 Pt 1): 738-740, indexed in Pubmed: 8164935.
31. Goldstein SR. Use of ultrasonohysterography for triage of perimenopausal patients with unexplained uterine bleeding. Am J Obstet Gynecol. 1994; 170(2): 565-570, doi: 10.1016/s0002-9378(94)70228-4, indexed in Pubmed: 8116714

32. Nicolaides KH, Syngelaki A, Ashoor G, et al. Noninvasive prenatal testing for fetal trisomies in a routinely screened first-trimester population. Am J Obstet Gynecol. 2012; 207(5): 374.e1-374.e6, doi: 10.1016/j. ajog.2012.08.033, indexed in Pubmed: 23107079.

33. Santiago AC, Quiroz LH, Shobeiri SA. Decreased Urethral Volume Is Comparable to Funneling as a Predictor of Intrinsic Sphincter Deficiency. Female Pelvic Med Reconstr Surg. 2017; 23(5): 336-342, doi: 10.1097/SPV.0000000000000386, indexed in Pubmed: 28118171.

34. Petros $\mathrm{PE}, \mathrm{Ulmsten} \mathrm{UI}$. An integral theory of female urinary incontinence. Experimental and clinical considerations. Acta Obstet Gynecol Scand Suppl. 1990; 153: 7-31, doi: 10.1111/j.1600-0412.1990.tb08027.x, indexed in Pubmed: 2093278.

35. Ulmsten $U$. The basic understanding and clinical results of tension-free vaginal tape for stress urinary incontinence. Urologe A. 2001; 40(4): 269-273, doi: 10.1007/s001200170035, indexed in Pubmed: 11490859. 